\title{
"NUESTRAS HUELLAS. MUJERES FORMOSEÑAS." COMENTARIOS Y REFLEXIONES SOBRE LAS POSIBILIDADES Y LIMITACIONES DE SU USO PARA LA ENSEÑANZA DE LA HISTORIA PROVINCIAL DESDE UNA PERSPECTIVA DE GÉNERO
}

\author{
"Our footprints. Women from Formosa." Comments and reflections on the \\ possibilities and limitations of its use for the teaching of provincial history \\ from a gender perspective
}

\author{
Mariela Leguizamón* \\ https://orcid.org/0000-0002-1572-7283,
}

\section{Resumen}

En este trabajo describimos y analizamos parte de una colección titulada "Nuestras Huellas. Mujeres Formoseñas.” La colección, emprendida por la Secretaría de la Mujer de la provincia de Formosa, pretende ser un aporte a la historia de las mujeres. Nos proponemos reflexionar sobre las posibilidades y limitaciones que ofrece la misma para la enseñanza de historia provincial desde una perspectiva de género.

$$
<\text { Historia de las mujeres }><\text { Género }><\text { Formosa }>
$$

\section{Abstract}

In this work we describe and analyze part of a collection entitled "Our Footprints. Women from Formosa." The collection, undertaken by the Secretariat of Women of the province of Formosa, aims to be a contribution to the history of women. We propose to reflect on the possibilities and limitations that it offers for the teaching of provincial history from a gender perspective.

$$
<\text { History of women }><\text { Gender }><\text { Formosa }>
$$

Recibido: 08/05/2019

Aceptado: 10/07/2019

\footnotetext{
* Instituto de Investigaciones Geohistóricas (IIGHI), CONICET, Resistencia, Argentina. marielajleguizamon@yahoo.com
} 
Leguizamón. Nuestras huellas. Mujeres formoseñas." Comentarios y reflexiones sobre las posibilidades y...

\section{Introducción ${ }^{1}$}

En el año 2009 la Secretaría de la Mujer del Gobierno de la provincia de Formosa, presentó la primera parte de "Nuestras Huellas. Mujeres Formoseñas". Se trata de una colección de biografías de Mujeres que, según este organismo, tuvieron protagonismo en lo político, educativo, cultural, religioso, etc. A la primera parte le sucedieron otras en los años siguientes, ${ }^{2}$ la colección, que hasta el momento incluye cinco partes, pretende ser un aporte a la historia de la mujer en Formosa. En el prólogo de la primera parte, Ana María del Riccio señalaba estas intenciones: "aportar a la historia, dar lugar a las Voces de Mujeres que expresen y relaten sus experiencias de vida, dejen enseñanzas y constituyan un estímulo para las nuevas generaciones."3 Tres partes de esta colección (I, III y IV) se encuentran en el Portal Oficial de la provincia en formato descargable. ${ }^{4}$

Aquí reflexionamos sobre las posibilidades y limitaciones de estos materiales para la enseñanza de una historia provincial que contemple la perspectiva de género. Es decir, una historia inclusiva, que contribuya a un análisis crítico sobre las formas de discriminación y desigualdad que se producen en la sociedad. La insistencia sobre la enseñanza de la historia en clave provincial -presente en los discursos, las leyes y los diseños curriculares de la provincia de Formosa-, y la búsqueda infructuosa de estudios historiográficos que ausculten el papel de la mujer en la vida formoseña, ${ }^{5}$ suscitaron el encuentro con esta colección.

La calidad y el contenido de estos materiales, nos interrogó sobre las posibilidades de su uso en el ámbito escolar. Su accesibilidad y la preocupación por incorporar la perspectiva señalada en el aula, particularmente al Seminario: Realidad Sociocultural de Formosa ${ }^{6}$, que se dicta en el Instituto Superior de Formación Docente "República Federal de Alemania" -en la ciudad de El Colorado de la Provincia de Formosa- nos impulsó a sistematizar su contenido para examinarlo críticamente. Así nacieron estos comentarios, cuyo análisis se sustenta, fundamentalmente, en los aportes historiográficos de la historia de las mujeres con perspectiva de género.

\footnotetext{
1 Este trabajo es la versión final de un conjunto de borradores que circuló entre colegas, quienes con sus comentarios y sugerencias ayudaron a enriquecerlo. Agradezco a la Dra. María Del Mar Solís Carnicer, a las Licenciadas Gabriela Alucín y Delia Pereira, y a la Prof. Mariel Galli por esa lectura atenta.

2 La segunda parte fue presentada en la IX Feria Provincial y la VIII Feria Internacional del libro de Formosa "Orlando Van Bredam" realizada en junio del 2010. La tercera parte fue presentada el 8 de marzo del 2011, en el marco de las actividades que la Secretaría de la Mujer desarrolló en conmemoración al día internacional de la mujer. Lo mismo sucedió con la cuarta parte al año siguiente.

3 Nuestras Huellas. Mujeres Formoseñas. Parte I, 2009, p. 7.

4 Se accede a ellos a través del siguiente link https://www.formosa.gob.ar/mujer/nuestrashuellas/documentos

5 La historiografía de Formosa es reciente, existen sujetos, temas y períodos históricos que aún no han sido abordados por los historiadores, en consecuencia, son áreas de vacancia.

${ }^{6}$ Este Seminario, forma parte de los diseños curriculares de todas las carreras que se dictan en los Institutos de la provincia.
} 


\section{Las mujeres como sujeto histórico: algunas consideraciones}

Las relaciones de género han sido constitutivas de la vida en todos los tiempos y geografías. Sin embargo, tal como señala (Barrancos, 2005), los estudios sobre la historia de las mujeres o desde la perspectiva de género, reconocen vínculos más recientes. Haciendo un recuento de ello, la autora señaló como un "elemento promisorio", que para mediados de los años noventa esta perspectiva contaba con historiadoras bien formadas en áreas regionales "dedicadas en su mayoría a tornar visible a las olvidadas mujeres del interior.” (Barrancos, 2005, p. 61). Su balance general pone en evidencia los avances realizados, pero también "auscultamientos históricos que aún aguardan abordajes", el registro de "una nítida hegemonía de espacios geográficos: Buenos Aires en primerísimo lugar" al que le siguen algunas grandes ciudades, es uno de ellos. ${ }^{7}$

La historia de las mujeres, no solo se propone visibilizar el papel de la mujer como sujeto de la historia, y a partir de ello complejizar la mirada de los procesos históricos, sino que, desde la perspectiva de género ${ }^{8}$ va más allá, al poner la mirada sobre las relaciones entre los sexos, desentrañando la condición de la mujer como producto de una construcción socio-cultural e histórica y proponiendo la igualdad de género. Estudios encarados desde esta perspectiva, mostraron, que más allá del papel de las "heroínas", los procesos de inclusión abiertos en algunos períodos históricos y las conquistas realizadas por las femeninas, la desigualdad de género y el juego pendular de inclusión/ exclusión, sin importar las latitudes, ha tenido una continuidad histórica.

La categoría de género aportada por Scott (1996), para el análisis histórico, y los trabajos de Lagrave (1990), Yannoulas (1993), Morgade (2001), García (2006), Di Liscia (2006), Barrancos (2002, 2007, 2008), Anzorena (2008), Lobato (2008), Valobra (2010), entre otros, dan cuenta de las conquistas de las mujeres en diferentes ámbitos, así como las nuevas y viejas formas de discriminación y desigualdad que han operado alrededor de las mismas, lo que ha puesto en discusión una idea tan consolidada en el sentido común como: la "liberación femenina". También han hecho notar, las reticencias que aún provocan oen términos de Barracos (2008), "la polvareda" que aún levanta el tratamiento de esta temática.

\footnotetext{
7 En su balance la autora plantea que los aspectos centrales que presenta la historiografía de las mujeres en la Argentina pueden situarse -además del mencionado-entre los siguientes tópicos: predominio epocal de fines del siglo XIX y primeras décadas del XX. Los análisis han priorizado la acción del movimiento de mujeres/movimiento feminista. Se destacan los análisis en torno de figuras precursoras o muy destacadas, así como su inscripción política e ideológica. Se corrobora una inclinación hacia las trabajadoras de ciertas ramas industriales y de servicios (textiles, frigoríficos, telefonía, industria pesquera, magisterio). También hay un amplio abordaje de la prostitución. Los análisis de mediados del siglo XX han relevado sobre todo la figura central del peronismo -Eva Perón- y a las mujeres identificadas con esta expresión política. Las principales dimensiones para otear la condición femenina se han ceñido a salud e higienismo, política, familia, educación y trabajo. Barrancos Dora "Historia, historiografía y género. Notas para la memoria de sus vínculos en la Argentina.” En: Revista La Aljaba. Segunda época. Vol IX, 2005. Pág. 64. Recuperado de: $\mathrm{http}: / / w w w . s c i e l o . o r g . a r / p d f / a l j a b a / v 9 / v 9 a 03 . p d f$

8 Entendemos el concepto en el sentido que postula Joan Scott. "El género: una categoría útil para el análisis histórico" (En: Cangiano, María Cecilia y Dubois, Lindsay, 1996).
} 
Leguizamón. Nuestras huellas. Mujeres formoseñas." Comentarios y reflexiones sobre las posibilidades y...

Hace algunos años la socióloga Lagrave (1990) se preguntaba ¿cómo es posible que las desigualdades persistan y cada vez se la vea menos? La historia de las mujeres con perspectiva de género ha mostrado que el progreso cuantitativo de las mujeres no es sinónimo de inclusión, que el patriarcado se recicla y los medios de comunicación de masas colaboran con este oscurantismo, difundiendo selectivamente testimonios y retratos de las superwomen, lo que lleva al sentido común a proclamar la igualdad de los sexos e incluso en los últimos años, a afirmar el vertiginoso ascenso de las mujeres.

A pesar de los avances producidos en el campo historiográfico, en las leyes educativas, la capacitación docente y la enseñanza, las mujeres como sujeto histórico y sus luchas, no son tenidas en cuenta como temática a enseñar, "el tema aparece nominalmente, en alguna efeméride (el día de la mujer, generalmente) y no vuelve a trabajarse pues el tema "está dado" (Valobra, 2010, p. 3). Un "habitus docente y escolar tradicionalista", una "escritura demasiado académica" para el público general, así como la falta de "recursos didácticos," son algunas de las causas señaladas por la autora, que contribuyen a lo "intratable" de su enseñanza. Sin embargo, "la escuela debería preocuparse por incorporar a las mujeres como sujeto histórico como una forma de plantear una mirada crítica a las formas de discriminación y desigualdad que se producen en la sociedad y que difunden persistentemente los medios." (De Amézola, 2008, p. 108).

Considerando estos planteamientos, y dado la vacancia de la temática en la historiografía de Formosa y la facilidad de acceso a tres partes de la colección "Nuestras huellas. Mujeres formoseñas", en las páginas que siguen, analizamos su contenido y reflexionamos sobre las posibilidades y limitaciones de su uso en la enseñanza de la historia provincial.

\section{Los contenidos y el relato de la colección "Nuestras huellas. Mujeres formoseñas"}

Como ya señalamos, la colección cuenta con cinco partes, sin embargo, nuestros comentarios y reflexiones se refieren a las partes I, III y IV, que son las que se pueden consultar a través del Portal Oficial.

La primera parte contiene la biografía de cuarenta y dos mujeres, la mayoría son mujeres "blancas", aunque se describe el accionar de una mujer de la etnia Toba (Qom) Ema Cuañeri y de Crescencia Villaba, única aborigen graduada de maestra normal, cargo que desempeñó en el colegio Santa Clara de la localidad de San Francisco de Laihsí. No todas estas mujeres son nacidas en Formosa, algunas son oriundas de Paraguay, Chaco y Buenos Aires que se radicaron en Formosa desde pequeñas en el seno de una familia. Otras vinieron a ejercer la profesión de maestras luego de ser designadas por el Estado Nacional o bien por decisión propia en búsqueda de trabajo.

Respecto de la profesión, la mayoría de estas mujeres fueron maestras normales y se dedicaron a esa tarea, algunas avanzaron en estudios superiores como el caso de Norma Ahída del Rosso, quien obtuvo el Título de Nutricionista y también ocupó cargos políticos como Convencional Constituyente y Diputada Provincial. Otras se dedicaron al comercio o incursionaron en actividades vinculadas con el arte como la escritura, la 
poesía, la música y el periodismo. Con todo, la mayoría de ellas desempeñó profesiones "típicamente femeninas" alcanzando, algunas, a ocupar cargos relevantes en el ámbito político, educativo y artístico.

Ser maestras, enfermeras y parteras, era considerado una "profesión de mujeres". Estudios como los de Di Liscia (2006), Yannoulas (1993), Anzorena (2008), entre otros, han revelado que la feminización de la docencia fue un proceso que se desarrolló a nivel mundial, pero en nuestro país se produjo de forma acelerada desde finales del XIX y principios del XX. Argumentos tales como: la paciencia, el sacrificio, el altruismo, etc. cualidades "naturalmente femeninas" además de un asunto de costos, efectivizaron la feminización de la docencia. Lo mismo sucedió con las enfermeras y parteras, dos profesiones auxiliares de la medicina, ejercida fundamentalmente por los varones. Las mujeres eran ante todo madres y estaban habituadas a aplicar las órdenes masculinas y al cuidado de los otros: limpiar desechos, brindar remedios, consolar y acompañar a los enfermos.

La colección también refiere a la filiación política de las mujeres. En este sentido es oportuno mencionar que, el ordenamiento político y jurídico de Formosa fue tardío. Primero, por la falta de autonomía, (Formosa se incorporó a los territorios del Estado Nacional en la segunda mitad del siglo XIX, y mantuvo ese estatus hasta 1955); luego, las continuas interrupciones institucionales impidieron, a quienes resultaron gobierno, culminar sus mandatos. Al término de la última dictadura en 1983, y hasta la actualidad, la provincia estuvo gobernada ininterrumpidamente por el Justicialismo. Los pocos estudios historiográficos que analizan las prácticas políticas y ciudadanas en el ámbito provincial, no han reconocido la participación de la mujer en el devenir histórico de Formosa. Sin embargo, podemos asegurar su presencia e intervención en los procesos que jalonaron la historia de la provincia. Ello es así, porque, aunque resulte una obviedad, como dice Barracos (1999), el "mundo es mundo gracias a la participación de ambos sexos."

En 1957, dos años después de la provincialización -lograda en 1955 durante la Presidencia de Juan Domingo Perón- se sancionó la constitución provincial en cuya elaboración participaron 24 convencionales, entre ellos dos mujeres: Rosa De Jesús Pastore de Tarantini de la Unión Cívica Radical Intransigente y Norma Ahída Del Rosso del Partido Demócrata Cristiano. En referencia a la filiación política de las mujeres, el tomo I de "Nuestras Huellas" alude a militantes del Justicialismo o que tuvieron participación en las filas de ese partido, ya sea formando parte de la delegación de la comisión pro-provincialización en 1955, en la resistencia peronista "luche y vuelve" luego del derrocamiento de Perón en 1955, como organizadoras de la rama femenina del partido, etc. No hay mujeres pertenecientes a otros partidos políticos, salvo Norma Ahída Del Rosso -ya mencionada- vinculada a la fundación del Partido Demócrata Cristiano. En 1981, Norma Ahída del Rosso recordaba el contexto en que se sancionaba la Constitución provincial:

"Situémonos por un instante en Formosa 1957. Dejábamos de ser Territorio Nacional y se nos colocaba en la coyuntura histórica de establecer el ordenamiento jurídico-político 
Leguizamón. Nuestras huellas. Mujeres formoseñas." Comentarios y reflexiones sobre las posibilidades y...

para levantar el complejo edificio del Estado Provincial (...) con las limitaciones de "hacer políticamente" que todos aún recordamos. (...) A la mayoría de nosotros nos faltaba entrenamiento, fogueo político, experiencia en el manejo de formas y de hechos. Nos faltó la formación integral en las aulas superiores de la alta política, que son los grandes laboratorios de conocimiento de los fenómenos políticos y sociales."

Aunque Norma no lo dice, podemos leer implícitamente en sus palabras, que las faltas de entrenamiento político, no solo aluden a la ausencia de autonomía provincial y los vaivenes impuestos por las intervenciones, sino también a cuestiones genéricas. Aunque, nada sabemos de las alocuciones, las dinámicas y relaciones de trabajo de estas dos mujeres con sus colegas en el seno de la asamblea, su presencia, sin duda, matiza la hegemonía patriarcal, y revela el dispar lugar de las mujeres en los espacios decisorios en esta coyuntura.

En el prólogo también se señala, que la obra se inscribe en "El modelo formoseño", cuyo conductor es Gildo Insfrán, gobernador de la provincia desde 1995. Este modelo ${ }^{10}$, según se explica, permite a todas las mujeres sin distinción "nuevas oportunidades y participación" ya que, para el gobernador, la mujer es "el motor estratégico de las transformaciones (...) del proyecto político hacia la Formosa del 2015" ${ }^{\prime 1}$. Su presencia en la militancia no cabe duda, a juzgar por el contenido de este libro. Cabría, sin embargo, preguntarse por el nivel de su participación en los espacios decisorios. La mayoría de las mujeres son portadoras de cualidades tales como: la amabilidad, sinceridad, pulcritud, por su trabajo desinteresado o ad honorem, por su entrega y amor, por el servicio a los demás ya sea los familiares, los enfermos o el partido.

La parte III, se compone con la biografía de veintitrés mujeres, la mayoría de ellas son nacidas en Formosa y las restantes son oriundas de Paraguay y provincias vecinas. Respecto de la profesión o actividad de las mujeres, la mayoría son maestras, médicas, artesanas, unas pocas comerciantes y una modista. Algunas de ellas son destacadas por haber ocupado cargos relevantes en algún área del gobierno. Por ejemplo, se destaca la participación de Arminda Del Carmen Colman, quien en el año 2000 fue Ministra del Superior Tribunal de Justicia, situación que es considerada un "hito" por ser la primera vez en la historia del Poder Judicial que una mujer llegara a formar parte del alto cuerpo. Otras destacadas por ocupar altos cargos públicos son: Marta

\footnotetext{
9 Nuevo Diario, 28 de noviembre de 1981.

${ }^{10}$ El Modelo Formoseño se basa en la Doctrina Peronista. Desde el punto de visto histórico, la periodización que propone se constituye a través de tres hitos: "la fundación de Formosa" (1979), "la provincialización" (1955) y "el modelo formoseño" (1995). Así, el panteón de héroes provinciales estaría constituido por: Jorge Luis Fontana, fundador de la ciudad de Formosa, el Pueblo junto a Juan Domingo Perón como hacedores de la provincialización y Gildo Insfran, el creador y conductor del modelo formoseño. Esta periodización, desconoce la complejidad del proceso histórico provincial, elimina otros sujetos de la historia provincial, funde la historia provincial con el peronismo. Es un relato lineal, armónico y claramente reduccionista.

${ }^{11}$ Nuestras Huellas. Mujeres Formoseñas. Parte I, 2009, p. 8.
} 
Mesa (Maestra, Diputada Provincial y Nacional durante el período 1999-2002), Matilde Mendez de Salon (Maestra Normal jubilada y Presidenta de la Liga Argentina contra el Cáncer) y Pabla Idoyaga (quien estuvo a cargo de la Subsecretaria de Educación de la Provincia durante el período 1987-1995). También son biografiadas dos empleadas del Poder Judicial que relatan muy sintéticamente los años difíciles de la última dictadura cívico militar en el ámbito provincial. De todas ellas hay una sola representante de la etnia Qom, se trata de la artesana Delfina Arias quien desde 1973 a la fecha ocupa un cargo en el Ministerio de Educación.

Respecto de la filiación política, cuatro mujeres se presentan como militantes justicialistas y dos como militantes sociales y políticas, aun así, todas las mujeres de este tomo se reconocen peronistas, admiradoras de Perón, Evita, Cristina o Insfrán. En esta parte no se hace referencia al "Modelo Formoseño" sino, a mujeres cuyas historias de vida hablan de "esfuerzo, entrega, solidaridad, coraje, y sobre todo mucho amor puesto al servicio del bien común"12.

Efectivamente, las mujeres biografiadas son presentadas como trabajadoras incansables, abnegadas, generosas, siempre dispuestas para los demás. Es decir, una mirada esencialista, que atribuye a "un cuerpo de mujer" el bien o lo bueno. Sin embargo, ello no es garantía de una "conciencia feminista" o una "subjetividad capaz de oponerse a las jerarquías de género," como dice Barrancos (2007, 2008), cuando señala que, aunque se producen cambios, no basta la sola presencia de mujeres en las instituciones públicas, ya sea en cargos legislativos o de gestión, para avanzar en derechos.

En este sentido, es importante señalar que, una de las mujeres de este tomo, Dora Regini Llano, calificada como "todo un ejemplo de mujer" por la "eficacia y capacidad en todos los ámbitos donde desarrolló sus actividades" "13, estaría implicada en delitos de lesa humanidad. Mirian Daldovo ${ }^{14}$, quien sufrió secuestro y detención en el contexto de la última dictadura cívico-militar de 1976, y posteriormente estuvo detenida en la Alcaidía de Mujeres, cuya jefatura estaba a cargo dicha médica, calificó a Regini como "una torturadora psíquica."

En efecto, esta mujer luego de recibirse de Maestra Normal y obtener el título de Doctora en Medicina Médica, ${ }^{15}$ ingresó a la Fuerza Policial en 1972 donde hizo carrera, ascendiendo a Comisario Principal y ocupando desde entonces numerosos cargos en distintas dependencias como: Directora del Hospital de El Colorado, Jefa del

\footnotetext{
${ }^{12}$ Nuestras huellas. Mujeres formoseñas. Parte III, 2011, p. 3.

${ }^{13}$ Nuestras huellas. Mujeres formoseñas. Parte III, 2011, p. 50.

${ }^{14}$ Mirian, fue detenida en 1977, tenía 22 años, estudiaba Ingeniería Forestal (cursaba el cuarto año), y trabajaba en el Instituto Universitario de Formosa. No tenía militancia política partidaria, integraba el Centro de Estudiantes que luchaba por una Universidad para Formosa. Tras ser liberada, estuvo con libertad vigilada. Nunca volvió a su trabajo y tampoco continuó sus estudios, ya que la obligaron a renunciar y aunque gestionó la reincorporaron para continuar su carrera, nunca le respondieron. Entrevista. Realizada en la ciudad de Formosa, el 20 de enero del 2015.

${ }^{15}$ Sus estudios universitarios se desarrollaron en Córdoba, al terminar el 4 año de la carrera de medicina, continuó sus estudios en la República Oriental del Uruguay donde obtuvo el título de Doctora en Medicina, título que fue revalidado den la Facultad de Medicina de la Universidad Nacional de Buenos Aires. Nuestras huellas. Mujeres formoseñas. Tomo III, 2011, p. 49.
} 
Leguizamón. Nuestras huellas. Mujeres formoseñas." Comentarios y reflexiones sobre las posibilidades y...

Servicio Sanitario de Aborígenes, Directora de Acción Social, Interventora de IASEP, Médica Municipal de Formosa, Jefa de la Alcaidía Provincial de Mujeres entre otros, fue condecorada con la Medalla de Honor al Mérito por la Federación Médica de Formosa. Sin embargo, en el marco del segundo juicio por delitos de lesa humanidad sustanciados en la provincia, la justicia ordenó a la fiscalía: extraer testimoniales de las declaraciones de testigos, de las que surgían denuncias formales e informales contra varias personas, entre ellas la directora de la Alcaidía Provincial de mujeres. ${ }^{16}$

La parte IV contiene la biografía de treinta mujeres, y al igual que en los anteriores, ellas son nacidas en Formosa, oriundas de Paraguay y provincias vecinas. Respecto de la profesión o actividad, la mayoría se ha desempeñado como parteras, enfermeras, maestras, aun cuando alguna de ellas es presentada como deportista, comerciante, obstétrica, etc. se han iniciado en la docencia, se han dedicado después a ella o han encarado desde ese lugar la creación de instituciones vinculadas a la educación o el cuidado del otro. Mercedes Espinoza, por ejemplo, siendo enfermera impulsó la creación de la carrera de Enfermería Universitaria en la Universidad Nacional de Formosa en la que también fue docente. Del mismo modo, Clotilde Tuduri De Rosi -presentada como Artista Plástica- trabajó como profesora en distintos colegios, fue Directora de Cultura durante el gobierno de Sosa Laprida (1966-1973) y responsable del mural 5 de octubre que fue declarado Patrimonio Histórico de Formosa.

Otras mujeres, como Demetria Tolaba, es rescatada por su "edad", por "buena madre" y por ser su casa una suerte de tertulia de políticos. Los aspectos que se resaltan de la vida de esta mujer de 103 años, analfabeta y trabajadora doméstica es que:

"Toda su vida prácticamente se dedicó a trabajar para poder alimentar a sus hijos, antes [dice el texto] recibía la visita de políticos y referentes partidarios quienes escuchaban sus consejos y sus apreciaciones sobre determinadas cosas y situaciones de interés para la comunidad"17.

Aunque los 103 años de Demetria, sugieren una amplia experiencia y la posibilidad de conocimientos acerca un territorio que es apenas un poco mayor a ella si se tiene en cuenta la fecha de fundación (1879), y bastante menor si se tiene en cuenta la provincialización (1955), que, sin embargo, no se incorporaron a su biografía. El texto, en cambio, repone un lugar común de las mujeres que, como señala Barrancos (2001) cuando analiza un libro de Luis Mohor: La mujer y la política, no puede sorprender: Demetria contribuye, al igual que la matrona de ese libro con su hijo, desde su propio "hogar" a las transformaciones sociales de su comunidad aconsejando a los políticos.

Este tomo, también contiene la biografía de dirigentes políticas, empleadas municipales y mujeres pertenecientes a los pueblos originarios como: María Ortiz de El Potrillo, Mema de la etnia Wichí y la dirigente Qom Sara Elena Torrent, Presidenta de

\footnotetext{
${ }^{16}$ Ver fundamentos de la sentencia en la Causa No 3119 caratulada: Camicha Juan Carlos y otros s/ asociación ilícita, privación ilegítima de la libertad. p. 344.

${ }^{17}$ Nuestras huellas. Mujeres formoseñas. Parte IV, 2012, p. 64.
} 
la Asociación Mujeres Artesanas Qomlashepi con sede en Barrio Nanqom, considerada una líder social destacada en la provincia. En lo que respecta a las militancias político partidarias, sucede igual que en los tomos anteriores, la mayoría de estas mujeres adscriben al peronismo, pues se reconocen admiradoras de los principales líderes de ese partido. Con la excepción de una sola mujer que perteneció al socialismo y fue admiradora de Alicia Moreau de Justo, se trata de la artista plástica Clotilde Tuduri De Rosi ya citada.

\section{Posibilidades y limitaciones de "Nuestras huellas. Mujeres formoseñas" para la enseñanza de la historia provincial desde una perspectiva de género}

Hace algunos años, un historiador reflexionaba, que los historiadores de comienzos del siglo XXI deberían enfrentar el desafío “...de superar el viejo esquema tradicional que tenía como protagonistas esenciales a los grupos dominantes -políticos, económicos y culturales- de las sociedades desarrolladas y dejaba al margen de la historia a los pueblos y grupos subalternos, incluida la inmensa mayoría de las mujeres" (Fontana, 2003, p.19). En dicha oportunidad, este autor también advertía, que el destinatario principal del trabajo de los historiadores debería ser el ciudadano corriente, el de "calle" y no la "tribu de los iniciados" u otros profesionales. El ciudadano común -decía Fontana- necesita de la historia, como cualquier ser humano, pues una de las funciones que cumple la historia para todo grupo es proporcionarle un sentido de identidad. Pero, cuando "los profesionales de la investigación o de la enseñanza no les proporcionamos el tipo de historia que necesitan, la reciben de manera asistemática, pero muy eficaz, de los políticos, de los "tertulianos" de la radio y la televisión, de las celebraciones conmemorativas (el tono y el sentido de las cuales viene determinado, en última instancia, de la institución que las paga)" (Fontana, 2003, p.16).

Las mujeres incluidas en la colección que analizamos, son presentadas en unas pocas páginas a través de un relato lineal y armónico, que poco contribuye a la comprensión del proceso histórico provincial. Se rescata del "olvido" a ciertas mujeres que han incursionado en el campo político, económico, social y cultural, y principalmente a militantes peronistas, pero sin tener en cuenta un análisis relacional. Se destaca con "pompa -, y a veces, con alharaca-, algunos desempeños mientras se oscurecen otros" (Barrancos, 2002, p.10). La información que ofrece -lugar de nacimiento, padres, hermanos, esposos e hijos, estudios, profesión o actividad y filiación política- si bien registra su presencia en el devenir provincial, no alcanza para elucidar los cambios operados en las relaciones sociales, económicas y políticas en los distintos períodos históricos.

Las limitaciones que presenta la escritura del libro, es otro aspecto a señalar. En la sección de "agradecimientos", se nombra a las responsables de coordinar, analizar y revisar las entrevistas realizadas a las protagonistas de la obra y a personas cercanas a ellas. Pero la información recogida a través de esta metodología, ni se analiza críticamente, ni se contrasta con otras fuentes. En el relato -además de cuestiones de coherencia- aparecen mezcladas las apreciaciones directas de las protagonistas, es decir, las mujeres entrevistadas, junto a las descripciones que realizan quienes escriben estas 
Leguizamón. Nuestras huellas. Mujeres formoseñas." Comentarios y reflexiones sobre las posibilidades y...

biografías. Así, las voces se confunden, porque las protagonistas no siempre se citan entre comillas o separadas de la narración que se construye sobre ellas.

Finalmente, el sesgo político partidario horada toda la colección. Ello se advierte a través de varios puntos de entradas que se señalan a continuación:

1. El primero de ellos, es el título elegido por quienes realizan la colección para acompañar la fotografía que presenta a las mujeres. ${ }^{18}$ Por ejemplo: Carmen Aguilar Azar "Militante de la Rama Femenina", Gladis Merladina Gonzales "Una trabajadora de la salud, militante peronista", Josefina Lavia de Nielsen "Un compromiso con la docencia y la causa peronista", Blanca Adelaida Rosario Padilla de Mancebo "Una militante de la causa peronista", Elena Eva Ramos de Carrizo "1era. Delegada de la Rama Femenina. Pirané", Esperanza Pilar Romea de Formosa "Activa militante Peronista", ${ }^{19}$ La fotografía de Dalia Díaz, América Argentina Lemos, Francisca Coria y Nilda Barbosa Negrita se acompaña con el título de "Militante Justicialista", y Elsa Beatriz Danielli como una "Militante Justicialista y social. ${ }^{20}$

El resto de las mujeres no son presentadas por su filiación política, sin embargo, en el relato que se hace de ellas se rescata la adhesión-participación a ese partido, así se hace con: Máxima Leoncia Barros de Navarreta "Primera docente mujer del departamento Patiño", Argentina Cerdán "Empresaria, Gremialista y Política", Ibis Blanca Fernández de De la Rosa "Docente- Militante Política", Leonor Martínez de Albornoz "Docente- militante", ${ }^{21}$ Yola Yoli "Cantante", Guillermina Alonzo "Mujer Artesana", Lidia Formica "Referente y promotora Salud Mujer", María Aquilina Torres de Paniagua "Militante Social y Política", en tanto que a Teodola Dolores Báez, Felisa Báez B. de Molina y Margarita Agustina Formosa se las presenta como "Referente Comunitaria", etc. ${ }^{22}$ cuando esto no ocurre, no se explicita el partido de partencia a excepción de Ahída Del Rosso y de Clotilde Tuduri del Rosi.

2. El segundo punto de entrada al relato legitimador es la utilización que se hace de las representaciones políticas de las mujeres biografiadas. Estas aluden a figuras o eventos vinculados al Partido Justicialista que las narradoras retoman. Por ejemplo, de Matilde Mendez de Salom, las relatoras dicen, que ella:

“(...) se siente representada por Eva Duarte de Perón por su liderazgo y capacidad que demostró en su joven vida y que alcanzó proyectos sociales que aún disfrutamos todas las mujeres, Libreta Cívica, el Voto femenino, Ley de Jubilación, vacaciones pagas que todo disfrutamos gracias a su gestión"

\footnotetext{
${ }^{18}$ Esto se observa fundamentalmente en la Parte I (2009) y III (2011) mientras que en la Parte IV (2012) el título hace referencia a su desempeño profesional o actividad laboral "docente", "comerciante", "Partera" Religiosa" etc.

19 Todas ellas se encuentran en la Parte I (2009).

${ }^{20}$ Ellas se encuentran en la Parte III (2011).

${ }^{21}$ Nuestras huellas. Mujeres formoseñas. Parte I (2009).

${ }^{22}$ Nuestras huellas. Mujeres formosenas. Parte III (2011).

${ }^{23}$ Nuestras huellas. Mujeres formoseñas. Parte III, 2009, p. 40.
} 
En similar sentido, ocurre con Guillermina Alonzo. Quienes escriben, hablan de ella retomando su pensamiento y percepción sobre determinados eventos. Se explica, por ejemplo, que:

"Se inició en la actividad política cuando obtuvo su libreta de identidad, gracias a la intervención de María Eva Duarte de Perón, afiliándose al partido justicialista, es allí cuando comienza a trabajar para el partido" 24 .

Otras veces, la voz de las entrevistadas asoma con mayor nitidez. Así ocurre con María Pinto a quien se cita textualmente y en negrita:

\section{"La mujer estaba detrás del hombre, no tenía ni voz ni voto, la voz y el voto lo tenía el hombre, cosa que cambia con Evita, la mujer camina a la par de ellos"25.}

Para las biografiadas la inclusión de la mujer en la arena política, fue una conquista del peronismo. Sin duda, la larga lucha por el sufragio femenino se alcanzó en 1947, con el advenimiento de este Partido. Pero, no podemos desconocer la campaña encabezada por Perón y Evita para "legitimar y modelar la ciudadanía dentro del movimiento peronista. La "evitización/peronización” de la ley, vació "la genealogía feminista sufragista” previa, cuya predica de inclusión, como lo señalan Valobra (2010), Barrancos (2007) y Lobato (2008) entre otras, preparó el camino para la sanción de la ley que otorgó derechos políticos a las mujeres. No obstante, las representaciones de las mujeres biografiadas anclan este logro en las figuras de Perón y Evita. Amparadas en las voces y representaciones de las mujeres, en el libro se construye un relato homogéneo.

Las particularidades de la historia política de la provincia, contribuyeron a que el establecimiento de estructuras partidarias a escala regional, fuera tardía, y que con la provincialización -lograda durante la Presidencia de Juan Domingo Perónse construyera una identidad que ligaba la autonomía provincial y la inclusión de derechos con el peronismo, aspecto que será explotado por el justicialismo desde entonces. Ya en el contexto electoral de 1983, la Secretaría de la Mujer del Partido Justicialista apelaba a la ciudadanía a recordar que nadie había luchado y hecho "tanto por la mujer" como su partido:

"Porque el Justicialismo nos amparó en la maternidad y en el trabajo./ Porque gracias al Justicialismo las mujeres votamos y podemos ser elegidas./ No lo olvides ante las posturas pretendidamente progresistas" 26

En las biografías, las figuras históricas del Partido Justicialista se anudan al "hito" de la provincialización. Por ejemplo, la biografía de Elena Eva Ramos de Carrizo dice:

\footnotetext{
${ }^{24}$ Nuestras huellas. Mujeres formoseñas. Parte III, 2011, p. 18.

${ }^{25}$ Nuestras huellas. Mujeres formoseñas. Parte I, 209, p. 82.

${ }^{26}$ Diario La Mañana, 28 de octubre de 1983.
} 
Leguizamón. Nuestras huellas. Mujeres formoseñas." Comentarios y reflexiones sobre las posibilidades y...

"Uno de los hechos que recuerda con emoción es el de aquel octubre de 1953, cuando el general Perón Visitó Formosa, jóvenes, trabajadores de obrajes, ancianos y otros, nos subimos al tren para venir a la capital y recibirlo. En ese tiempo se hablaba de la necesidad de la provincialización y era Perón el único que podía acceder a nuestro pedido."27

Las mujeres evocan momentos previos o posteriores a este "hito histórico", así como sus percepciones sobre esos acontecimientos que luego las narradoras retoman, construyendo un discurso lineal y romántico. En otras biografias, se reponen acciones de algunas mujeres peronistas integrantes de la Rama Femenina del partido, como las tareas de difusión y propaganda que realizó Elsa Quiroga "con altos parlantes y vehículos por los distintos barrios" o que, "Viajó junto a la Delegación de Provincialización y vivió uno de los momentos más inolvidables que fue el encuentro con "el General Perón en la histórica jornada del 5 de abril de 1955 (...)"28. O las acciones de Elena Carrizo -Subdelegada de la Rama Femenina del partido- quien, "a su corta edad" -dicen las narradoras- "visitaba casa por casa a las familias informando a las mujeres el significado de esta agrupación y sus objetivos, como así también la importancia del derecho al voto (...)"29.

En la biografía de Florencia Balestra "Chiquita", se evocan otro proceso histórico: el derrocamiento de Perón, la proscripción del partido y las acciones vinculadas a la clandestinidad en1955. Aquí, no se ocupan de sus padres, marido o hijos, el relato se inicia de la siguiente manera:

"Mujer clorindense, peronista de alma, militante activa durante toda su vida al servicio de la causa nacional y popular. Elegante, agradable, de carácter fuerte y decidida; ella como dirigente atesoraba un recuerdo y un orgullo muy íntimo, haber sido correo del General Perón y vínculo entre las compañeras y el líder, radicado por ese entonces en Asunción del Paraguay." 30

En el caso de Dalila Díaz, se citan sus evocaciones textualmente, estas refieren a la coyuntura del proceso dictatorial de 1976, dice Dalila:

"En esas noches negras del proceso militar caminábamos en silencio llevando entre nuestras ropas alguna ayuda de mercadería para algunas familias de compañeros que los habían llevado, pero eso nunca nos detuvo, ni tuvimos miedo, al contrario, nos dio más fuerza para defender a nuestro peronismo en estos momentos. ${ }^{.31}$

\footnotetext{
${ }^{27}$ Nuestras huellas. Mujeres formoseñas. Parte I, 2009, p. 91.

${ }^{28}$ Nuestras huellas. Mujeres formoseñas. Parte I, 2009, p. 86.

${ }^{29}$ Nuestras huellas. Mujeres formoseñas. Parte I, 2009, p. 90.

${ }^{30}$ Nuestras huellas. Mujeres formoseñas. Parte III, 2011, p. 72.

${ }^{31}$ Nuestras huellas. Mujeres formoseñas. Parte III, 2011, p. 8.
} 
3. Un último punto de entrada para señalar es el recurso a la comparación. Se entabla un paralelismo entre la vieja y la nueva Formosa, es decir, entre la etapa territoriana y provincial con el nuevo modelo formoseño. Esto permite enumerar, desde el relato, las obras realizadas por el gobierno en los últimos años, legitimando así la política oficial y la gestión de Gildo Insfrán. Aquí también, aparecen confusas las descripciones y percepciones de quienes narran y las voces de las mujeres biografiadas o de las entrevistadas. A continuación exponemos algunos ejemplos:

Yola-Yoli. Es presentada como cantante y como en otras biografías se empieza narrando sobre su familia y sus estudios, posteriormente se rescata el hecho de que Yoli ha sido "embajadora de la cultura provincial" para seguidamente decir, que fue una "ferviente admiradora del gobierno de Gildo Insfrán." Aunque ya fallecida sus "trascendentes pensamientos" están presentes en el manifestar de su hija. Quien "trasmite las más altas posturas ideológicas políticas, realzando la política social e igualitaria del Gral. Perón $(\ldots)^{32}$.

María Aquilina Torres de Paniagua. Presentada como militante social y política, s responsable de un Centro Comunitario y asiste con almuerzo y merienda a ciento cincuenta chicos con ayuda de Nación:

"Relata [dicen las narradoras] con otros gobiernos nuestra ciudad nunca progresaba, en cambio, ahora se ve el progreso y el crecimiento, a lo largo y a lo ancho de toda la provincia. (...) tenemos el reconocimiento a nivel nacional gracias a la gestión de nuestro gobernador el doctor Gildo Insfrán (...)"33.

Eleuteria Roa (Muñeca). Es presentada como Intendente de Villafañe, ocupó ese cargo en los siguientes períodos 1995- 1999, 1999-2003, 2007-2011 у 20112015, fue Concejal entre los años 2005-2007. Se rescata su origen humilde, el rol que asumió tras la muerte de su madre, su participación en las Ligas Agrarias Formoseñas y particularmente que formó parte del grupo de productores que en 1973 presentó un petitorio reclamando: créditos, títulos de propiedad, energía eléctrica entre otros, luego de ello se explica "La mayoría de estas peticiones se concretaron durante el gobierno del Dr. Gildo Insfrán ${ }^{34}$.

En el caso de Celia Nequi de Corvallan, el relato es similar al anterior. Es decir, se narra en primer lugar su nacimiento en el seno de una familia humilde, su función de "buena madre" tras sufrir el abandono de su primera pareja y finalmente su militancia en el partido justicialista, el trabajo realizado junto al resto de su familia para el regreso de Perón y su lugar de funcionaria. Fue Concejal por dos períodos y Presidenta del Consejo Deliberante de Laguna Yema. A través de su figura se legitima la de su hijo, Luis Alberto Corvallan, Intendente de la localidad quien en el 2012 ocupaba ese cargo por cuarta vez consecutiva y que -una vez más- se inscribe en "El Modelo Formoseño."

\footnotetext{
${ }^{32}$ Nuestras huellas. Mujeres formoseñas. Parte III, 2011, p. 14.

${ }^{33}$ Nuestras huellas. Mujeres formoseñas. Parte III, 2011, p. 32.

${ }^{34}$ Nuestras huellas. Mujeres formoseñas. Parte IV, 2012, p. 95.
} 
Leguizamón. Nuestras huellas. Mujeres formoseñas." Comentarios y reflexiones sobre las posibilidades y...

Las prácticas políticas de Celia implícitas en la siguiente cita, bien podrían inscribirse en el estilo político clientelar del peronismo, ${ }^{35}$ aunque claro está, que esa no es la intencionalidad de la narración pues se explica que:
"ella tenía una vocación de ayudar a los más humildes y brindaba a toda la población de Laguna Yema todo lo que ellos necesitaban, nadie salía de su casa sin llevar lo que venían a pedir, ella era completamente feliz porque su vocación era lo social." ${ }^{36}$

El paralelismo entre la vieja y nueva Formosa se expresa a través de un relato en el que "ella no murió" sino que está presente, no solo en el corazón de la gente, sino porque sigue siendo parte "de la transformación de su pueblo" a través de la figura de su hijo, el Intendente de Laguna Yema, quien "heredó su amor a la política y al servicio de la gente" para posteriormente enumerar los cambios producidos en la localidad convertida en "un lugar pujante y lleno de oportunidades" 37.

Otro tanto ocurre con las mujeres pertenecientes a la población aborigen como Miguelita Quintana de Misión Pozo Yacaré. Esta mujer descendiente de padre wichí y madre criolla, "Partera empírica" "tiene un excelente trato con el gobierno de la provincia, debido al respeto hacia su cultura e historia." "Miguelita [dice el texto] al igual que toda su familia y la comunidad Wichí, reconocen que fue el gobernador Gildo Insfrán quien les devolvió la dignidad (...)"38 luego de lo cual se enumeran algunas acciones realizadas por el gobierno en el pueblo Misión Pozo Yacaré refundado en junio del 2011.

Los hechos sociales pueden leerse de muchas maneras, pero es fundamentalmente la teoría la que nos permite ver cosas que sin ellas no las veríamos. En este sentido, la categoría de género que se incorporó de manera lenta y desigual en los estudios históricos a partir de los años noventa, resulta insoslayable en tanto es "un elemento constitutivo de las relaciones sociales basado en las diferencias que se perciben entre los sexos; y una manera primaria de significar las relaciones de poder." (Scott, 1996, p. 9). El género se construye social y culturalmente a través de los símbolos que están disponibles y que evocan múltiples representaciones, así como de los conceptos normativos que definen sus interpretaciones y significados, y que se expresan en las instituciones, la política, la economía, el trabajo, etc. ¿Cuáles son las representaciones de género contenida la colección Nuestras Huellas-Mujeres formoseñas?

Como se habrá advertido, se refuerzan los estereotipos sociales tradicionales de género. Las mujeres son primordialmente hijas, esposas y sobre todo "buenas

\footnotetext{
${ }^{35}$ En el sentido que lo plantea Auyero (1997) es decir, el clientelismo político no solo como "favor a cambio de votos" sino también las redes interpersonales de lealtades, sentimientos, confianza, etc. que se manifiestan y expresan en esa relación, la representación o "performas" con que se otorgan los beneficios adherida a ellos. dicho en otros términos expresados por Auyero, "la cosa dada o el favor", no es sinónimo de chantaje sino de amor al pueblo, pues importa tanto "lo que se da" como "el cómo se lo da."

${ }^{36}$ El subrayado es nuestro. Nuestras huelas. Mujeres formoseñas. Parte IV, 2012, pp. 69-70.

${ }^{37}$ Nuestras huellas. Mujeres formoseñas. Parte IV, 2012, p. 70.

${ }^{38}$ Nuestras huellas. Mujeres formoseñas. Parte IV, 2012, p. 41.
} 
madres", que han legado a la provincia: "profesionales hombres y mujeres de bien". La dimensión pública y privada de las mujeres se inscribe en la "naturaleza femenina", se les atribuye y se atribuyen a sí mismas, un conjunto de cualidades que han sido socialmente naturalizados como femeninas y que aluden -más que a la razón- a la sensibilidad, desinterés, vocación, entrega, amor, compromiso social, etc. Cuando la voz de las mujeres biografiadas se escucha, la mayoría de ellas sostiene que

"La mujer y la política son un buen complemento. La mujer es visionaria, es intuitiva es altruista" 39 .

"La mujer tiene intuición y una sensibilidad especial que puede serle útil para desempeñarse en el ámbito político"40.

"La mujer al ser dadora de vida, hace que le ponga el corazón y por ende la sensibiliza en la toma de decisiones" 41 .

"La mujer en la política es un instrumento muy importante, ya que empieza a hacer política desde su hogar...así como puede traer un ser al mundo, mejor puede desempeñarse en un cargo"42. "La mujer puede desempeñarse en política en igualdad de condiciones que el hombre (...) por su especial sensibilidad y características de su género"43.

En definitiva, invocación de la maternidad y las virtudes femeninas asociadas a ella observables en los relatos y representaciones de las mujeres, invisibilizan la paternidad y son compatibles con la visión de Evita, para quien "la mujer estaba definida en términos naturaleza "femenina." "La mujer del pueblo que no era otra cosa que la mujer peronista, estaba dispuesta al sacrifico por los demás y era la guardiana del hogar" (Lobato, 2008, p.77) Así, es la "sensibilidad" y el rol maternal de las mujeres, lo que las habilita a la acción política. ${ }^{44}$

En resumen, las limitaciones de esta colección son muchas. Llama la atención, que la Secretaría de la Mujer -institución encargada de dar impulso a esta obra- haya obliterado la renovación conceptual ocurrida en el campo de estudio de las mujeres para elaborar las biografías. Al sesgo político partidario que, horada todo el libro, se suma la mirada estereotipada y binaria de las diferencias sexuales atribuyendo a las mujeres características "esenciales" que las distinguen de los hombres. Carece de objetividad y rigor científico, se inscribe en una lógica "panfletaria" y "contribucionista", adicionando

\footnotetext{
${ }^{39}$ Nuestras huellas. Mujeres formoseñas. Parte I, 2009, p. 92.

${ }^{40}$ Nuestras huellas. Mujeres formoseñas. Parte IV, 2012, p. 12.

${ }^{41}$ Nuestras huellas. Mujeres formoseñas. Parte IV, 2012, p. 47.

${ }^{42}$ Nuestras huellas. Mujeres formoseñas. Parte IV, 2012, p. 55.

${ }^{43}$ Nuestras huellas. Mujeres formoseñas. Parte IV, 2012, p. 72.

${ }^{44}$ Barrancos (2007) y Valobra (2010) entre otras, han planteado, que la visión que vincula las virtudes domésticas y los valores públicos no son privativos de Evita puesto, que constituían una moneda corriente en la vertiente principal del feminismo de la época, sin embargo, en el lenguaje de Eva adquirían un contrasentido al postular a la figura de Perón en un lugar de absoluta primacía. No obstante, con Eva invitó se politizó el hogar y se quebraron las fronteras entre lo público y lo privado, al mismo tiempo que se imponían límites a los derechos políticos alcanzados.
} 
Leguizamón. Nuestras huellas. Mujeres formoseñas." Comentarios y reflexiones sobre las posibilidades y...

mujeres a la historia de la provincia y en particular a la historia del peronismo formoseño. Más que una contribución a la historia de las mujeres, la colección parece haber servido para legitimar un partido, un gobierno, y ciertos estereotipos de género. El sesgo político partidario y la forma en que se narra su vida contribuye, a nuestro modo de ver, a reforzar el orden social y político vigente en la provincia, así como estereotipos tradicionales de género y con ello relaciones desiguales de poder.

Si el objetivo es contribuir a la historia de las mujeres en el ámbito provincial, rescatarlas del olvido o el abandono, hacerlas visibles -como señala la Secretaría de la Mujer-esta historia debería estar más atenta a las voces de las mujeres que fueron entrevistadas, a sus subjetividades y representaciones. Las cuales, deberían ser sometidas a un análisis más riguroso, y desde marcos teóricos y metodológicos más apropiados, que eviten caer sesgos y revelen más sobre los procesos de subordinación y los juegos pendulares de inclusión/ exclusión que atravesó (y atraviesa) la vida de las mujeres en todos espacios, de los que Formosa no escapa.

Plantear sus limitaciones, no constituye un óbice para el uso de estos materiales en el ámbito escolar, más bien, advierten algunos aspectos que una historia con perspectiva de género no debe soslayar. La colección registra la participación de las mujeres en diferentes coyunturas del devenir histórico provincial, esta presencia, matiza la hegemonía patriarcal. De modo que puede servir para introducir el tema en el ámbito escolar, sin por ello caer en el esencialismo de que un cuerpo de mujer basta para producir cambios y relaciones más igualitarias. Más allá de sus limitaciones, las biografías ofrecen un conjunto de datos, silencios y omisiones, que los estudiantes pueden desentrañar con la guía de los docentes, la indagación y análisis de otras fuentes, y marcos teórico metodológicos apropiados para el abordaje de una historia de las mujeres. En este sentido, su utilización requerirá tener en cuenta las contribuciones historiográficas que -aunque en otras geografías- alumbraron sobre el trabajo, las luchas, la participación y biografías de las mujeres, y las relaciones de género en el ámbito público y privado. Así como las redes conceptuales aportadas por la perspectiva feminista y de género, algunas de las cuales fueron citadas en este trabajo.

Carecer de los abundantes recursos de que "disponen los poderes establecidos para alimentar la difusión de sus discursos" como sostiene (Fontana, 2003), no nos impide pensar, que "hay muchas formas en que podemos aproximarnos a las realidades locales." En este sentido, consideramos que todo recurso que sirva para pensar, y hacer pensar las relaciones de género en la escuela, siempre resulta auspicioso. Pero, los usos que hagamos de ellos dependen, en última instancia, de la amplitud teórica, el marco didáctico y la creatividad de quienes asuman, el abordaje de un tema, que aún provoca resistencias.

\section{Referencias bibliográficas}

Álvarez, A. M. (2000) “Movimiento feminista y redefinición de la realidad". Mujeres en red. Universidad de la Coruña. 
Anzorena, C. (2008) "La Participación de las Mujeres en el Proceso de formación del Estado Nacional en Argentina de finales del siglo XIX. Reflexiones desde una perspectiva de género". Revista Iberoamericana de Educación, № 45/2, 10 de febrero.

Barrancos, D. (2005) "Historia, historiografía y género. Notas para la memoria de sus vínculos en la Argentina”. Revista La Aljaba, Segunda época, Vol. IX.

Barracos, D. (2008) Mujeres entre la casa y la plaza. Buenos Aires: Editorial Sudamericana. Barrancos, D. (2007) Mujeres en la sociedad Argentina: Una historia de cinco siglos. Buenos Aires: Editorial Sudamericana.

Barracos, D. (2002) Inclusión/exclusión. Una historia con mujeres. Buenos Aires: Fondo de cultura económica.

De Amézola, G. (2008) Esquizohistoria. La historia que se enseña en la escuela, la que preocupa a los historiadores y una renovación posible de la historia escolar. Buenos Aires: Libros del zorzal.

Di Liscia, M. S. (2006) "Mujeres Argentinas en el siglo XIX”. En: Las Mujeres y sus luchas en la Historia Argentina. Presidencia de la Nación, pp. 53-62.

Fontana, J. (2003) ¿Qué historia enseñar?, Clío \& Asociados, $N^{\circ} 7$.

García, S. (2006) "Ni solas ni resignadas: la participación femenina en las actividades científicoacadémicas de la Argentina”. Cadernos Pagu, 27, julho-dezembro, pp. 133-172.

Lagrave, R. M. (1990) "Una emancipación bajo tutela. Educación y trabajo de las mujeres en el siglo xx” En: G. Duby y M. Perrot. Historia de las mujeres. España: Taurus, Tomo V.

Lobato, M. Z. (2008) ¿Tienen derechos las mujeres? Política y ciudadanía en la Argentina del Siglo XX. Buenos Aires: Editorial Capital Intelectual.

Yannoulas, S. C. (1993) "Educar: ¿una Profesión de Mujeres? La Feminización del Normalismo y la Docencia en Brasil y Argentina 1870-1930)". Revista Brasileira de Estudos Pedagógicos, V. 74, N¹78, pp.713-738.

Valobra, A. (2010) "La ciudadanía política femenina en la argentina de la primera mitad del siglo XX. Aportes para una aproximación conceptual y recursos didácticos”. Clio \& Asociados, 14, pp. 86- 122.

Valobra, A. (2010) Del hogar a las urnas. Recorridos de la ciudadanía política femenina: Argentina, 1946-1955. Rosario: Editorial Prohistoria.

Scott, J. (1996) "El género una categoría útil para el análisis histórico.” En: Cangiano, M. C. y Dubois, L. De mujer a Género. Teoría, representación y práctica feminista en las ciencias sociales. Buenos Aires: Centro Editor de América Latina.

\section{Fuentes:}

Nuevo Diario, 28 de noviembre de 1981.

Diario La Mañana, 28 de octubre de 1983.

Nuestras Huellas. Mujeres formoseñas, tomo I, año 2009.

Nuestras Huellas. Mujeres formoseñas, tomo II, año 2010.

Nuestras Huellas. Mujeres formoseñas, tomo III, año 2011.

Nuestras Huellas. Mujeres formoseñas, tomo IV, año 2012. 
